\title{
Overweight, obesity, and colorectal cancer screening: Disparity between men and women

\author{
Moonseong Heo ${ }^{1}$, David B Allison² and Kevin R Fontaine*3
}

Address: ${ }^{1}$ Department of Psychiatry, Weill Medical College of Cornell University, White Plains, NY, USA, ${ }^{2}$ Department of Biostatistics, Section on Statistical Genetics \& Clinical Nutrition Research Center, University of Alabama at Birmingham, Birmingham, AL, USA and ${ }^{3}$ Division of Rheumatology, Johns Hopkins University School of Medicine, Baltimore, MD, USA

Email: Moonseong Heo - moh2002@med.cornell.edu; David B Allison - dallison@uab.edu; Kevin R Fontaine* - kfontai1@jhmi.edu

* Corresponding author

Published: 08 November 2004

BMC Public Health 2004, 4:53 doi: I0.I I86/ I47|-2458-4-53
Received: 20 May 2004

Accepted: 08 November 2004

This article is available from: http://www.biomedcentral.com/I47/-2458/4/53

(C) 2004 Heo et al; licensee BioMed Central Ltd.

This is an Open Access article distributed under the terms of the Creative Commons Attribution License (http://creativecommons.org/licenses/by/2.0), which permits unrestricted use, distribution, and reproduction in any medium, provided the original work is properly cited.

\begin{abstract}
Background: To estimate the association between body-mass index (BMI: $\left.\mathrm{kg} / \mathrm{m}^{2}\right)$ and colorectal cancer (CRC) screening among US adults aged $\geq 50$ years.

Methods: Population-based data from the 200 I Behavioral Risk Factor Surveillance Survey. Adults $(N=84,284)$ aged $\geq 50$ years were classified by BMl as normal weight $(18.5-<25)$, overweight (25$<30)$, obesity class I $(30-<35)$, obesity class II $(35-<40)$, and obesity class III $(\geq 40)$. Interval since most recent screening fecal occult blood test (FOBT): $(0=>\mid$ year since last screening vs. $\mid=$ screened within the past year), and screening sigmoidoscopy (SIG): $(0=>5$ years since last screening vs. I = within the past 5 years) were the outcomes.

Results: Results differed between men and women. After adjusting for age, health insurance, race, and smoking, we found that, compared to normal weight men, men in the overweight (odds ratio [OR] I.25, $95 \% \mathrm{Cl}=1.05-\mathrm{I} .5 \mathrm{I})$ and obesity class I $(\mathrm{OR}=1.2 \mathrm{I}, 95 \% \mathrm{Cl}=1.03-1.75)$ categories were more likely to have obtained a screening SIG within the previous 5 years, while women in the obesity class I (OR $=0.86,95 \% \mathrm{Cl}=0.78-0.94)$ and II $(\mathrm{OR}=0.88,95 \% \mathrm{Cl}=0.79-0.99)$ categories were less likely to have obtained a screening SIG compared to normal weight women. BMI was not associated with FOBT.
\end{abstract}

Conclusion: Weight may be a correlate of CRC screening behavior but in a different way between men and women.

\section{Background}

Colorectal cancer (CRC) is the third most common cancer in the United States with approximately 150,000 cases annually leading to about 57,000 annual deaths [1]. A prospective study of over 900,000 US adults found that, compared to normal weight adults, death rates from CRC were $20 \%$ to $84 \%$ higher in overweight and severely obese men and $10 \%$ to $46 \%$ higher in overweight and severely obese women [2]. Although other factors (e.g., age, family history) also contribute to CRC risk, obesity is a significant risk factor [1]. Thus, overweight and obese adults should consider obtaining regular CRC screening because early detection and intervention might reduce mortality $[1,3]$.

However, studies suggest that overweight and obese women are more likely to delay cervical and breast cancer screenings than normal weight women $[4,5]$. In contrast, 
data from the 2001 Behavioral Risk Factor Surveillance Survey (BRFSS) indicates that, among men, overweight and obesity associates with obtaining prostate-specific antigen testing (Fontaine, Heo \& Allison, under review). Although these cancers are sex-specific, the disparity led us to evaluate whether the obesity CRC screening association differed between men and women.

\section{Methods}

The Center for Disease Control and Prevention's BRFSS collects state-based data on preventive health practices and risk behaviors in the non-institutionalized civilian population aged $\geq 18$ years [6]. The analyses we report are derived from the 2001 BRFSS. Information on BRFSS design and sampling methods are reported elsewhere $[7,8]$.

\section{Study variables}

Body mass index (BMI; $\left.\mathrm{kg} / \mathrm{m}^{2}\right)$, calculated from selfreported weight and height, was the predictor.

Outcomes were interval since the most recent use of fecal occult blood test (FOBT), and sigmoidoscopy (SIG) in adults aged $\geq 50$ years who reported ever having had the respective screening examination. BRFSS codes FOBT responses as: 'within past year', 'within past 2 years', 'within past 5 years', '5 or more years ago', 'don't know/ not sure', or 'refused'. SIG is coded as: 'within past year', 'within past 2 years', 'within past 5 years', 'within past 10 years', '10 or more years ago', 'don't know/not sure', or 'refused'. Consistent with screening recommendations [1], we dichotomized FOBT as $0=>1$ year since last screening vs. 1 = screened within the past year. For SIG, the American Cancer Society recommends screening every 5 years for adults aged $\geq 50^{1}$. Thus, SIG was dichotomized as $0=>5$ years since last screening vs. $1=$ screened within the past 5 years.

We included age, education, race, income, self-reported general health status, smoking, employment, and health insurance as covariates.

\section{Statistical analysis}

We grouped respondents into 5 BMI-defined categories (18.5-<25 "normal weight", 25-<30 "overweight", 30$<35$ "obesity class I", 35-<40 "obesity class II", and $\geq 40$ "obesity class III"). Respondents ( $=250$; .3\%) with BMI's <18.5 ("underweight") were omitted from the analyses.

We used multivariate logistic regression to estimate BMIscreening associations by entering the BMI-defined categories and potential confounders into the model as either continuous (e.g., age [including polynomials up to the third order]) or dichotomous variables (e.g., health insur- ance). Using the guidelines proposed by Greenland [9], we retained covariates that were statistically significant at the two-sided 0.20 alpha level or caused $\mathrm{a} \geq 10 \%$ change in any of the BMI-defined categories when deleted. As a result, education, income, self-reported general health, and employment were omitted. Responses coded as 'don't know/not sure', or 'refused' were treated as missing variables and excluded from analyses, as were respondents with missing data on any covariates. To ensure unbiased general population estimates, we used sample weights provided by the BRFSS. BMI categories were investigated as 4 contrasts with the normal weight category serving as the referent.

To evaluate whether sex moderated the BMI-screening association, we ran adjusted logistic models that also included BMI $\times$ sex interaction terms. Finally, because we observed a significant BMI $\times$ sex interaction, we then analyzed the data for men and women separately. Analyses were performed with SPSS 11.5.

\section{Results}

The mean age of the respondents was 65 years $($ median $=$ 63). The mean BMI was 30.2 (median = 31) and $93 \%$ reported having health insurance. Less than half reported ever having either a screening FOBT or SIG (Table 1). Among those who ever had a screening examination $54.1 \%$ of men and $52.7 \%$ of women $\left(\chi^{2}(1)=6.61, \mathrm{p}=\right.$ $.010)$ reported obtaining a screening FOBT within the previous year, and $84.4 \%$ of men and $80.3 \%$ of women $\left(\chi^{2}(1)=98.4, \mathrm{p}<0.001\right)$ reported obtaining a screening SIG within the previous 5 years.

BMI was not associated with obtaining a FOBT (OR's ranged from 0.90 to 0.98 ). Compared to normal weight adults, however, those in the overweight $(\mathrm{OR}=1.15$, 95\%CI 1.02-1.31), obesity class I (1.21, 95\%CI 1.09 $1.35)$, II $(1.17,95 \%$ CI $1.04-1.44)$ and III $(1.27,95 \%$ CI 1.05-1.58) categories were more likely to have obtained a screening SIG within the previous 5 years ( $\mathrm{p}$ 's $<0.05)$.

The interaction effect between sex and BMI categories on FOBT was not significant $\left(\chi^{2}(4)=8.64, \mathrm{p}=.071\right)$. However, the interaction effect between sex and BMI categories on SIG screening was significant, $\left(\chi^{2}(4)=114.03, \mathrm{p}<\right.$ .0001). BMI was not associated with obtaining a FOBT for either sex (OR's ranged from 0.87 to 1.05). However, compared to normal weight men, men in the overweight (1.25, 95\%CI 1.05-1.51) and obesity class I (1.21 95\%CI 1.03-1.75) categories were significantly more likely to have obtained a screening SIG. In contrast, obesity class I (0.86 95\%CI 0.78-0.94) and II (0.88 95\%CI 0.79-0.99) women were less likely to have obtained a screening SIG compared to normal weight women (see Figure 1). 
Table I: Selected characteristics of respondents aged $\geq \mathbf{5 0}$ years

\begin{tabular}{|c|c|c|}
\hline Characteristic & Value* & $\mathbf{N}$ \\
\hline Age, yrs & $64.6 \pm 10.1$ & 84,284 \\
\hline Body mass index (BMl), kg/m² & $30.2 \pm 6.2$ & 84,284 \\
\hline \multicolumn{3}{|l|}{ Sex, \% } \\
\hline Men & 38.2 & 32,179 \\
\hline Women & 61.8 & 52,106 \\
\hline \multicolumn{3}{|l|}{ Race, \% } \\
\hline White & 82.3 & 68,639 \\
\hline Non-white & 17.7 & 14,778 \\
\hline \multicolumn{3}{|l|}{ Health insurance, $\%$} \\
\hline Yes & 93.0 & 78,260 \\
\hline No & 7.0 & 5,904 \\
\hline \multicolumn{3}{|l|}{ Smoking, \% } \\
\hline Current smoker & 18.2 & 15,265 \\
\hline Former smoker & 35.4 & 29,709 \\
\hline Never smoker & 46.4 & 38,959 \\
\hline \multicolumn{3}{|c|}{ Ever had fecal occult blood test (FOBT), \% } \\
\hline Yes & 43.0 & 37,498 \\
\hline No & 53.9 & 49,123 \\
\hline \multicolumn{3}{|c|}{ Ever had screening sigmoidoscopy (SIG), \% } \\
\hline Yes & 45.3 & 39,574 \\
\hline No & 51.1 & 46,584 \\
\hline \multicolumn{3}{|c|}{ Screening fecal occult blood test (FOBT), \% } \\
\hline within past year & 53.2 & 18,449 \\
\hline greater that I year & 46.8 & 16,238 \\
\hline \multicolumn{3}{|l|}{ Screening sigmoidoscopy (SIG), \% } \\
\hline within past 5 years & 81.8 & 30,465 \\
\hline greater than 5 years & 18.2 & 6,771 \\
\hline
\end{tabular}

\footnotetext{
* Plus-minus values are means \pm standard deviation
}

\section{Discussion}

These data support an association between BMI and obtaining a screening SIG within the previous 5 years, after smoking, health insurance, race, and age are taken into account. Moreover, the BMI-SIG associations were different between women and men. Women in the obesity class I and II categories were less likely to obtain SIG screening as a function of BMI. This is consistent with associations between BMI and delayed cervical and breast cancer screening $[4,5]$. On the other hand, men in the overweight and obesity class I categories were more likely to obtain a screening SIG.

The reasons for this disparity are unclear. Perhaps physicians encourage cancer screening more vigorously among their overweight and obese male patients. Differences between men and women on factors such as self-esteem and body image [10] may also contribute to explaining the differential BMI-screening associations. These speculations underscore the importance of identifying barriers that might deter overweight and obese women from obtaining screenings.
This study has limitations including: the BRFSS, a telephone survey, is prone to measurement error; because the BRFSS is an observational study, the BMI-screening associations could be due to residual confounding or confounding from unmeasured variables; the cross-sectional design did not allow testing causal inferences; and people without telephones, approximately $3 \%$ of the US population [6], are not surveyed through BRFSS.

\section{Conclusions}

These data indicate that weight may be a correlate of CRC screening behavior but in a different way for men and women.

\section{Competing interests}

The author(s) declare that they have no competing interests.

\section{Authors' contributions}

$\mathrm{MH}$ drafted the paper and assisted with the statistical analysis and interpretation. DB assisted with the writing of the manuscript and in the interpretation of the results. $\mathrm{KF}$ 


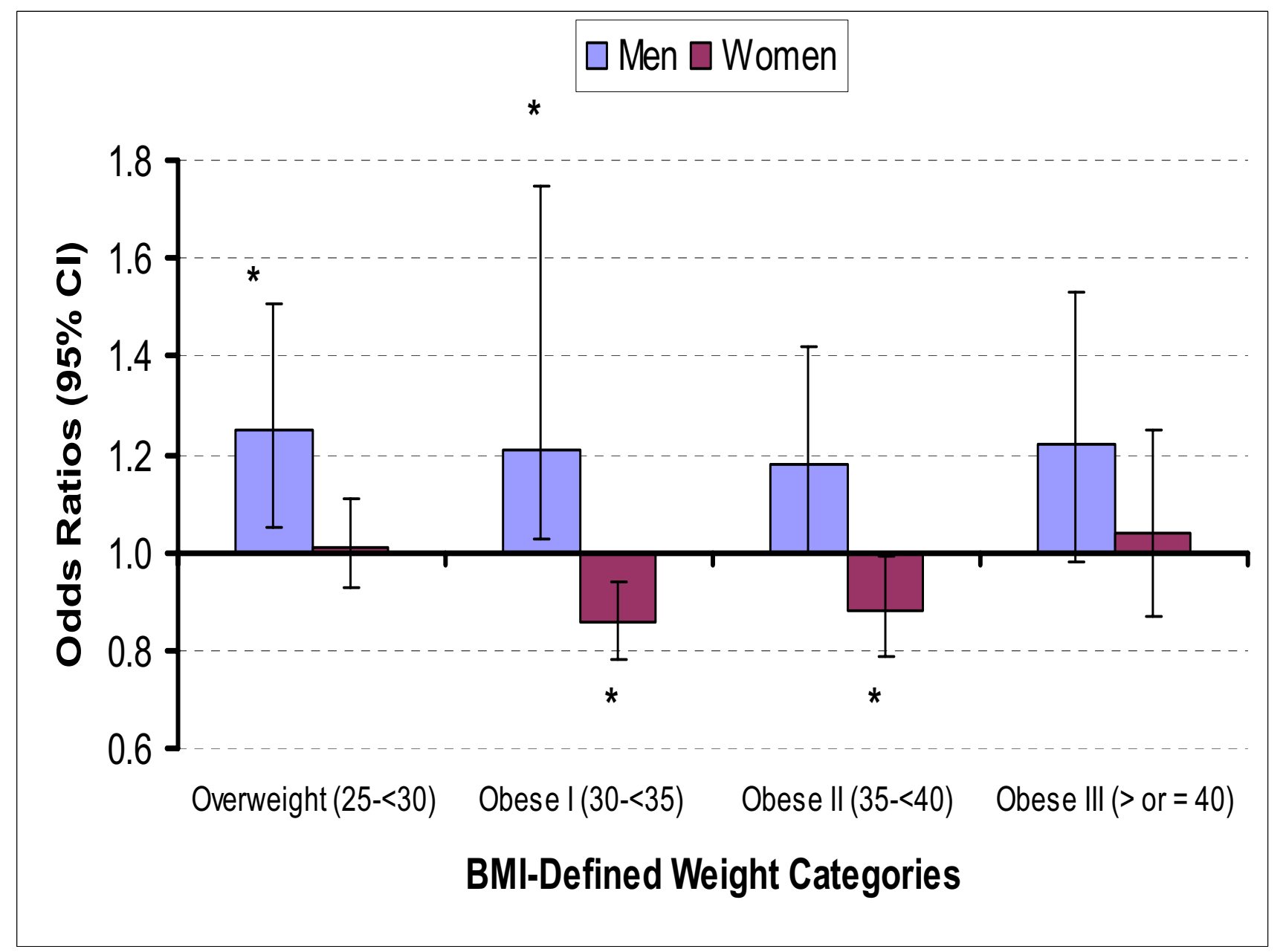

Figure I

Adjusted odds ratios (OR) for obtaining a screening sigmoidoscopy according to BMI-defined categories for men and women* Significantly different from normal weight reference group at $p<0.05$.

obtained and analyzed the data and assisted with the preparation of the manuscript.

\section{Acknowledgements}

Supported in part by grants from the Arthritis Foundation, the Blaustein Pain Research Fund, and NIH grant P30DK056336.

\section{References}

I. American Cancer Society: Cancer facts and figures, 2003. American Cancer Society. Atlanta GA; 2003.

2. Calle EE, Rodriguez C, Walker-Thurmond BA, Thun MJ: Overweight, obesity and mortality from cancer in a prospectively studied cohort of US adults. N Engl I Med 2003, 348:I 625-I638.

3. Edwards BK, Howe HL, Ries LAG, Thun MJ, Rosenberg HM, Yancik $R$, Wingo PA, Jemal A, Feigal EG: Annual report to the nation on the status of cancer, 1973-featuring implications of age and aging on US cancer burden. Cancer 1999, 94:2766-2792.
4. Fontaine $K R$, Heo M, Allison DB: Body weight and cancer screening among women. Journal of Women's Health and Gender-Based Medicine 200I, 10:463-470.

5. Wee CC, McCarthy EP, Davis RB, Phillips RS: Screening for cervical and breast cancer: Is obesity an unrecognized barrier to preventive care? Ann Intern Med 2000, 132:697-704.

6. Centers for Disease Control and Prevention: Health risks in America: Gaining insight from the Behavioral Risk Factor Surveillance Survey System. Atlanta, GA: US Department of Health and Human Services, Public Health Service, Centers for Disease Control and Prevention; 1997.

7. Centers for Disease Control and Prevention: 200I Behavioral Risk Factor Surveillance Survey- Users Manual. Atlanta, GA: US Department of Health and Human Services, Public Health Service, Centers for Disease Control and Prevention; 2002.

8. Gentry EM, Kalsbeek WD, Hogelin GC, Jones JT, Gaines KL, Forman MR, Marks JS, Trowbridge FL: The behavioral risk factor surveys: II Design, methods, and estimates from combined state data. Am J Prev Med 1985, I:9-14.

9. Greenland $\mathrm{S}$ : Modeling and variable selection in epidemiologic analysis. Am J Pub Health 1989, 79:340-349. 
10. Zayat EN, Fontaine KR, Cheskin LJ: Use of preventive health care services by patients with obesity. Obes Res 1999, 7:223.

\section{Pre-publication history}

The pre-publication history for this paper can be accessed here:

http://www.biomedcentral.com/1471-2458/4/53/prepub

Publish with BioMed Central and every scientist can read your work free of charge

"BioMed Central will be the most significant development for disseminating the results of biomedical research in our lifetime. " Sir Paul Nurse, Cancer Research UK

Your research papers will be:

- available free of charge to the entire biomedical community

- peer reviewed and published immediately upon acceptance

- cited in PubMed and archived on PubMed Central

- yours - you keep the copyright

Submit your manuscript here:

http://www.biomedcentral.com/info/publishing_adv.asp 